\title{
Innovation in 3D Braiding Technology and Its Applications
}

\author{
Caroline Emonts $*++^{(D)}$, Niels Grigat*, + (D), Felix Merkord, Ben Vollbrecht (D), Akram Idrissi, Johannes Sackmann (D) \\ and Thomas Gries (D)
}

Citation: Emonts, C.; Grigat, N.;

Merkord, F.; Vollbrecht, B.; Idrissi, A.; Sackmann, J.; Gries, T. Innovation in 3D Braiding Technology and Its Applications. Textiles 2021, 1, 185-205. https://doi.org/10.3390/textiles 1020009

Academic Editor: Philippe Boisse

Received: 29 May 2021

Accepted: 30 June 2021

Published: 7 July 2021

Publisher's Note: MDPI stays neutral with regard to jurisdictional claims in published maps and institutional affiliations.

Copyright: (c) 2021 by the authors. Licensee MDPI, Basel, Switzerland. This article is an open access article distributed under the terms and conditions of the Creative Commons Attribution (CC BY) license (https:// creativecommons.org/licenses/by/ $4.0 /)$.
Institut für Textiltechnik, RWTH Aachen University, Otto-Blumenthal-Straße 1, 52074 Aachen, Germany; felix.merkord@ita.rwth-aachen.de (F.M.); ben.vollbrecht@ita.rwth-aachen.de (B.V.); akram.idrissi@ita.rwth-aachen.de (A.I.); Johannes.Sackmann@ita.rwth-aachen.de (J.S.); thomas.gries@ita.rwth-aachen.de (T.G.)

* Correspondence: caroline.emonts@ita.rwth-aachen.de (C.E.); niels.grigat@ita.rwth-aachen.de (N.G.)

+ These authors contributed equally.

Abstract: Braids are generally divided into 2D braids and 3D braids. Two-dimensional braids include flat braids and circular braids. Circular braids represent three-dimensional textiles, as they enclose a volume, but consist of a two-dimensional yarn architecture. Three-dimensional braids are defined by a three-dimensional yarn architecture. Historically, 3D braids were produced on row and column braiding machines with Cartesian or radial machine beds, by bobbin movements around inlay yarns. Three-dimensional rotary braiding machines allow a more flexible braiding process, as the bobbins are moved via individually controlled horn gears and switches. Both braiding machines at the Institut für Textiltechnik (ITA) of RWTH Aachen University, Germany, are based on the principal of 3D rotary machines. The fully digitized 3D braiding machine with an Industry 4.0 standard enables the near-net-shape production of three-dimensionally braided textile preforms for lightweight applications. The preforms can be specifically reinforced in all three spatial directions according to the application. Complex 3D structures can be produced in just one process step due to the high degree of design freedom. The 3D hexagonal braiding technology is used in the field of medical textiles. The special shape of the horn gears and their hexagonal arrangement provides the densest packing of the bobbins on the machine bed. In addition, the lace braiding mechanism allows two bobbins to occupy the position between two horn gears, maximizing the number of bobbins. One of the main applications is the near-net-shape production of tubular structures, such as complex stent structures. Three-dimensional braiding offers many advantages compared to 2D braiding, e.g., production of complex three-dimensional geometries in one process step, connection of braided layers, production of cross-section changes and ramifications, and local reinforcement of technical textiles without additional process steps. In the following review, the latest developments in 3D braiding, the machine development of 3D braiding machines, as well as software and simulation developments are presented. In addition, various applications in the fields of lightweight construction and medical textiles are introduced.

Keywords: 3D braiding; 3D hexagonal braiding; 3D rotary braiding; medical textiles; lightweight materials

\section{Introduction}

The manufacturing process of braiding is one of the oldest crafting techniques in the history of humankind. It has been used to produce round braids, such as cords or ropes, and flat braids, such as strands. Based on the manual crafting technique, the method of maypole braiding (also known as circular braiding) has emerged as an automated processing technology. For the development of more complex braided structures, the technology of braiding has evolved over the years, so that the fields of application have progressed from the aforementioned simple, flat and round braids to three-dimensional structural geometries using 3D braiding technologies. In order to produce three-dimensional braids, 
circular braiding machines have been modified for the overbraiding of a tubular core. By the braiding of several layers on a core, a spatial 3D braid is created. However, with this technique the individually braided layers are not connected to each other and thus can be referred to as 2.5D braids [1]. For the production of 3D braids, Cartesian braiding machines, such as the two-step or four-step braiding machines, were developed [2-4]. On the one hand, these braiding machines are characterized by the intertwining of the processed yarns in all three spatial directions; on the other hand, they are still limited with regard to the direction of the bobbin's movement on the machine bed. Due to this limitation, the complexity of the 3D geometry produced with Cartesian braiding machines is limited. To increase the complexity of the geometry, 3D rotary braiding machines were developed, where the bobbins' movements are controlled individually via horn gears and flexible switches. Due to these developments in the machine technology for 3D braids, the fields of application have progressed from the aforementioned simple, flat and round braids to technical applications, where three-dimensional structural geometries are required. On the one hand, this includes the material group of fiber-reinforced materials, which can be used for lightweight solutions [5]. On the other hand, medical products such as stents or synthetic ligaments represent a wide range of possible applications for the latest $3 \mathrm{D}$ braiding machine technology [6-8]. The historical developments indicate how important new innovations in machine technology continually establish new areas of application in the field of technical textiles [8].

With an overview of the history and the beginnings of 3D braiding machine types, this review gives an introduction into how 3D braiding fabrics are defined and characterized. It specifically illustrates the development of 3D braiding machinery capable of fabricating complexly shaped three-dimensional structures and lightweight composite applications. At the Institut für Textiltechnik (ITA) of RWTH Aachen University, Germany, new developments have been made both in machine technology for the automated production of 3D braids and on the application side. The rotary 3D braiding machine and the $3 \mathrm{D}$ hexagonal braiding machine presented in this review represent the newest inventions made with regard to $3 \mathrm{D}$ braiding machine technology and its applications.

\section{Three-Dimensional Braiding Fabrics and Machine Types}

Braids are generally divided into 2D braids and 3D braids. Two-dimensional braids include flat braids and circular braids [9]. Although the latter represent three-dimensional textiles since they enclose a volume, they consist of a two-dimensional yarn architecture. Three-dimensional braids, on the other hand, have a three-dimensional yarn architecture [10]. They are also referred to as integral textiles and are characterized depending on the yarn orientation, the amount of yarn groups, and the integral yarn course of the braid's yarns. The integral yarn course is a crucial characteristic feature of 3D braiding. As the yarns cross the entire cross-section of the preform, they intertwine with the various yarn groups and connect the individual layers of the 3D braid [1]. Thus, a delamination of layers in the three-dimensional preform geometry is avoided and this significantly distinguishes 3D braids from 2D braids. Furthermore, the mentioned features of the 3D braiding technology allow the production of complex 3D braided structures for the medical sector $[6,7,11]$.

\subsection{Three-Dimensional Braiding Methods}

Three-dimensional braiding machines can be divided into Cartesian so called, "track and column" braiding machines as well as rotary braiding machines (see Figure 1). The two approaches differ fundamentally in the type of bobbin motion. 


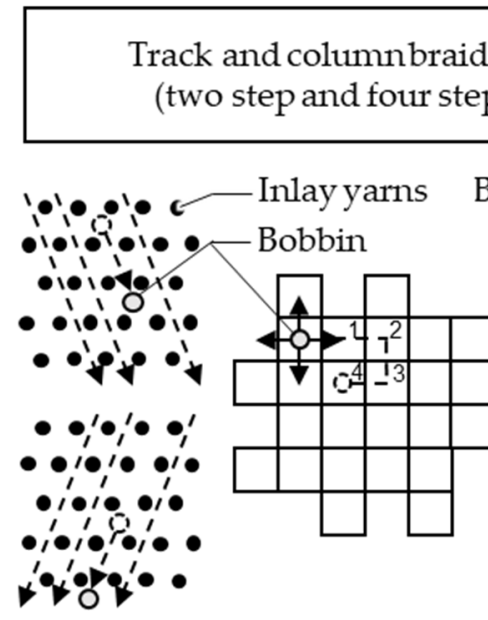

Cartesian machine bed

(a) (b)

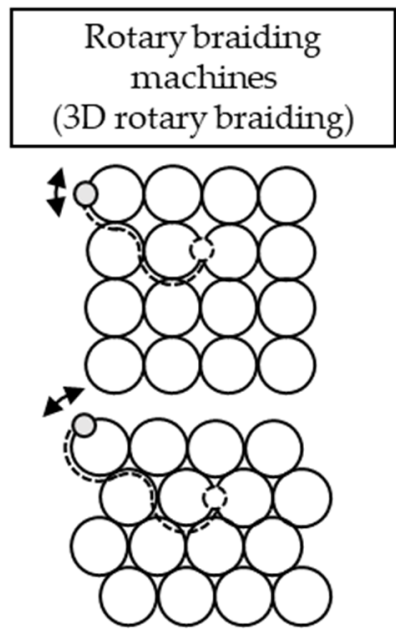

Square or hexagonal arrangment of horn gears

(c)

Figure 1. Comparison of track and column braiding machines with Cartesian (a) and circular (b) machine beds, as well as rotary braiding machines (c). Adapted from ref. [12].

The so-called row and column braiding machines consist of a rectangular or round machine bed on which the bobbins move in a Cartesian or radial way on concentric circles $[3,4]$. In the two-step process, inlay yarns are arranged in the shape of the desired product contour. In this way, the desired three-dimensional braiding structure is created by crossing the braiding threads and moving around the inlay yarns.

In the four-step braiding process, the bobbins are moved in four successive steps which describe one braid cycle. First the columns are shifted a specific distance in an alternating way and subsequently the tracks are moved alternately. The two last steps describe the reverse motion of steps one and two in order to move the tracks and columns to their initial position. This process can be used to produce preforms with square, rectangular, T-shaped, or I-shaped cross-sections. For the production of round profiles, the radial fourstep braiding process is suitable, in which the bobbins move in and between concentric circles [13].

From a technical point of view, rotary braiding machines are an extension of the horn gear technology of conventional braiding machines to an entire braiding bed. The square or hexagonal arrangement of the horn gears results in an arrangement that can be used to produce three-dimensional structures in addition to two-dimensional braids. Since the bobbins on each horn gear can move almost independently of each other in the rotatory braiding principle, it proves advantageous for producing complex braids [14].

In contrast to conventional packing braiding machines, the horn gear track concept can be extended to a trackless principle using horn gears and switching devices. The movement of the bobbins between the horn gears is realized by means of the switching devices. These are placed at the crossing points between the horn gears and allow the bobbins to be changed between the horn gears in a specific way. In addition to decoupling the movement of the two horn gears involved, this results in a doubling of the number of bobbins that can be used in the process. A comparison of conventional two-dimensional circular braiding, three-dimensional rotary braiding, and three-dimensional rotary braiding with switching devices regarding the bobbin movement is shown in Figure $2[12,15,16]$. 


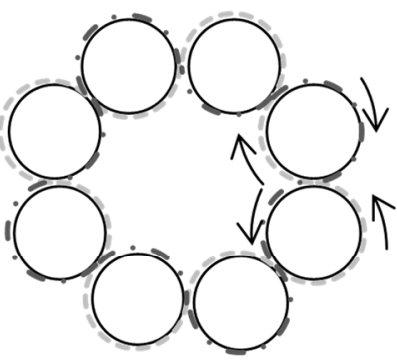

2-dimensional circular braiding

(a)

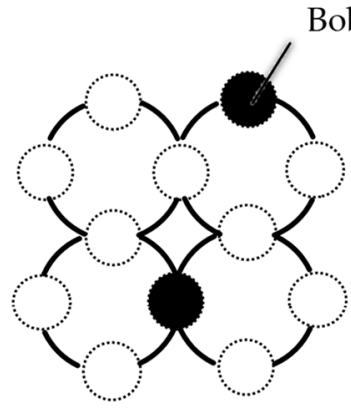

3-dimensional rotary braiding

(b)

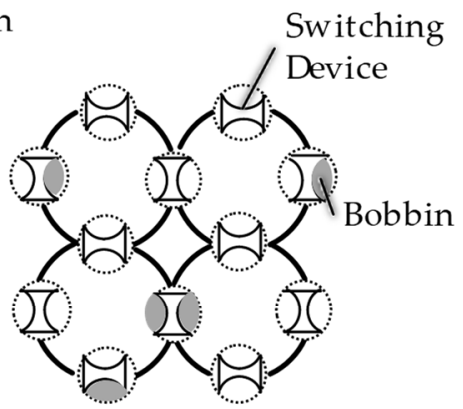

3-dimensional rotary braiding with switching device

(c)

Figure 2. Bobbin movements from (a) 2D circular braiding, (b) 3D rotary braiding, and (c) 3D rotary braiding with switching devices.

\subsection{Characteristics of 3D Braid Technology Process}

The properties of the 3D braids produced with the complex 3D braiding machine technology differ significantly from $2 \mathrm{D}$ braids but also implicate new challenges for the machine components and process control. This needs to be taken into account when $3 \mathrm{D}$ braiding technology is further developed.

When looking at the bobbin's movements on a 3D rotary braiding machine (see Figure 3), it can be seen that the individual yarn length changes depending on the bobbin's position on the machine bed.

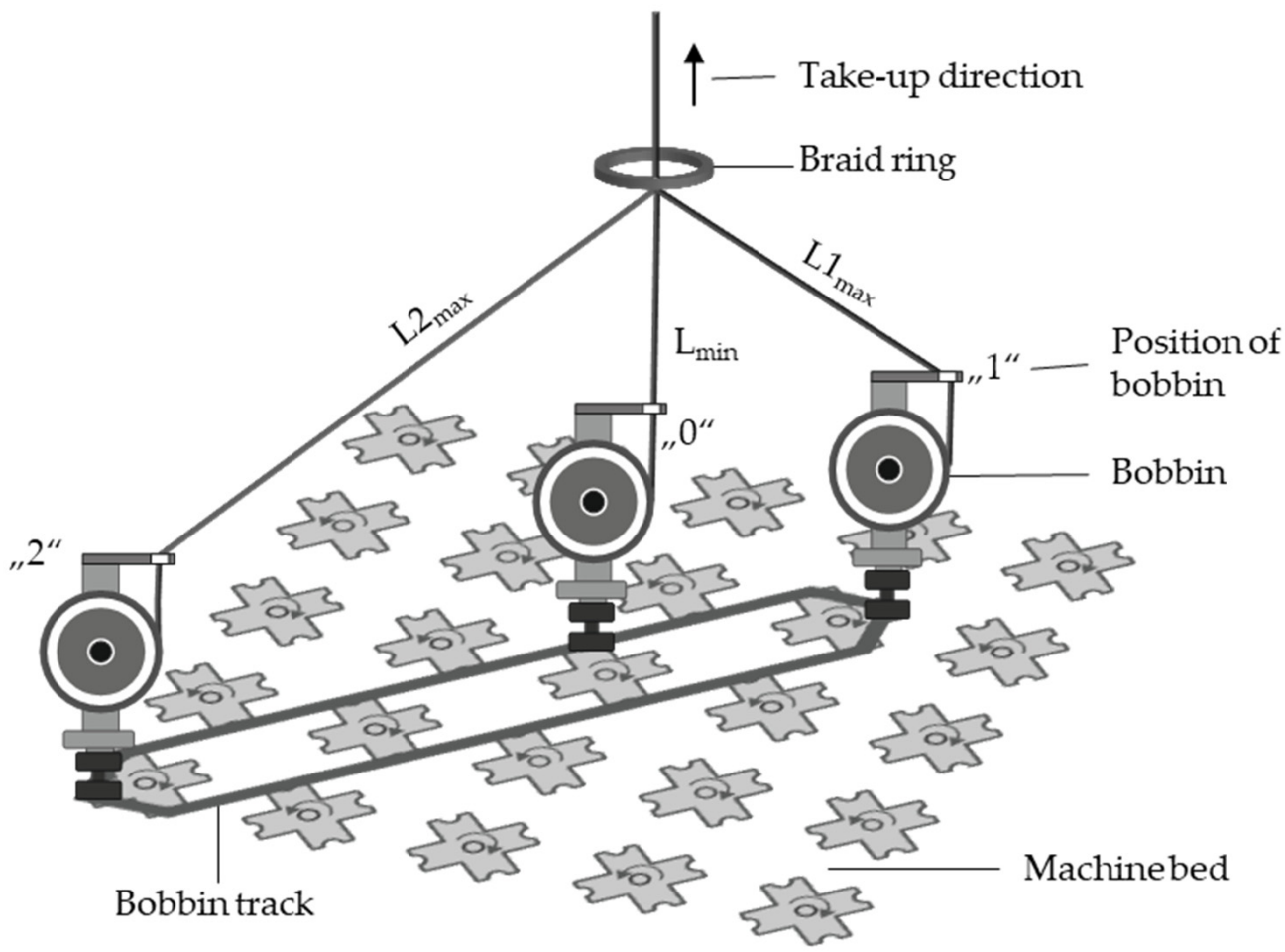

Figure 3. Illustration of yarn length compensation in 3D braiding technology depending on the bobbin's position on the machine bed. 
In Figure 3 an example of the machine bed of a 3D braiding machine with $5 \times 5$ horn gears is illustrated. Three different positions of the bobbin are shown on the drawn bobbin track. Depending on the position of the bobbin, the yarn length differs. If the bobbin is positioned directly below the braiding ring, this corresponds to position " 0 " with the minimum yarn length " $\mathrm{L}_{\mathrm{min}}$ ". Depending on the distance of the bobbin to the position " 0 ", the thread length increases. The positions " 1 " and " 2 " refer to possible positions of the bobbins on the machine bed along the bobbin track. The difference between the maximum and minimum yarn length is called the yarn length compensation $\Delta \mathrm{L}$.

$$
\Delta \mathrm{L}=\mathrm{L}_{1,2 \max }-\mathrm{L}_{\min }
$$

The yarn length corresponds to the distance of the top end of the bobbin to the braiding point. The greater the maximum distance of the bobbin to the center of the machine bed, the greater the yarn path compensation will be. Furthermore, the yarn path compensation depends on the height of the braiding point. The bigger the distance between the braiding point and the bobbin, the smaller the yarn path compensation. To counteract this yarn path compensation, the bobbins must contain a retracting spring that ensures constant yarn tension in the 3D braiding process. As the yarn length decreases while the bobbin returns towards the position " 0 ", the spring pulls back the yarn to compensate the decreasing yarn length and thus ensures a constant yarn tension. Such constant yarn tension is of crucial importance for high quality braids. Due to the constant winding and unwinding of the fibers due to the yarn path compensation, increased friction occurs between the yarns and the yarn guiding elements in the 3D braiding process. Increased friction also occurs between the individual yarns, since more yarns cross during 3D braiding compared to the $2 \mathrm{D}$ braiding technology. The higher the number of crossing yarn groups, the stronger the fiber-to-fiber friction. Since 3D braiding technology is used in particular for technically demanding products, it is important to minimize the friction caused by the complex 3D braiding process. On the one hand, this involves the use of low-friction yarn guiding elements and, on the other hand, the bobbins need to be designed accordingly. Depending on the processed material, the bobbin's predetermined tension is adjusted with help of the integrated spring. The spring is also used to determine the compaction and density of the braided preform.

\section{Machine Developments for Lightweight and Medical Applications}

As shown in Section 2.1, there are various machine concepts for the braiding of 3D preforms. The machines are classified according to various characteristics, such as the drive concept and its control, the number of bobbins, or the materials to be processed. This section describes two 3D braiding machines that have been further developed at ITA and which are used for research of materials and products for lightweight and medical applications.

\subsection{Rotary 3D Braiding Machine}

The rotary 3D braiding machines shown in Figure 4 are the conventional Herzog 3D rotary packing braiding machine for so-called "packing braids" and the "9-module" 3D rotary braider, which consists of nine modules with $4 \times 4$ horn gear arrangements [1,17]. 


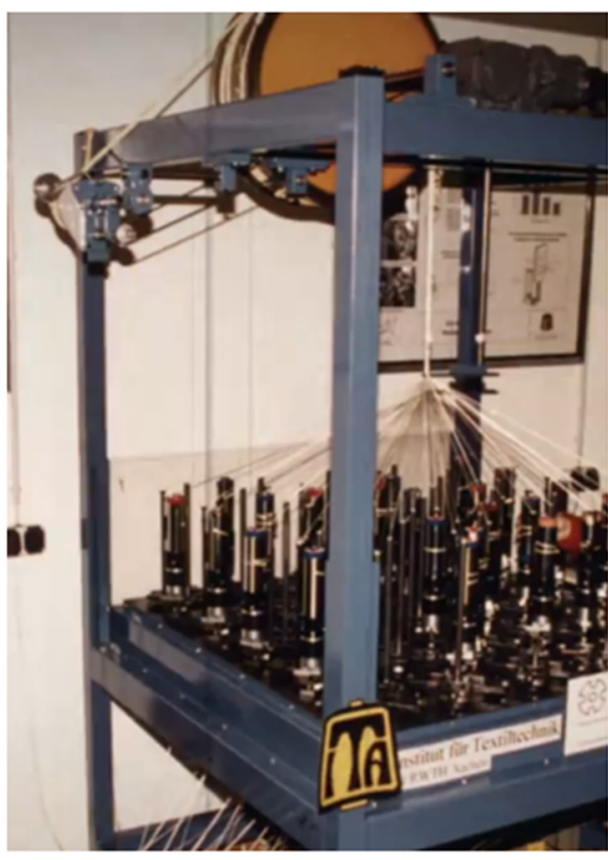

(a)

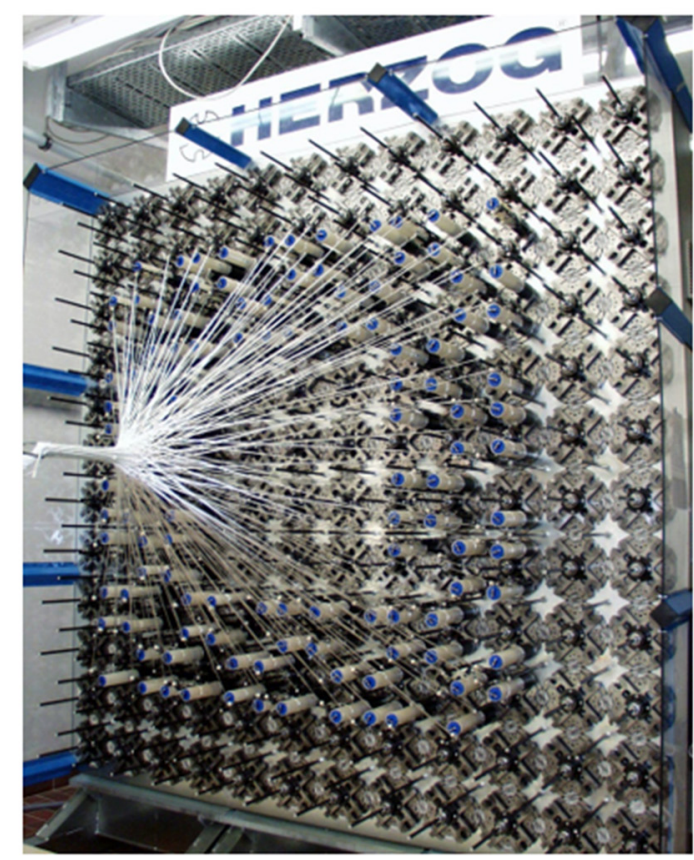

(b)

Figure 4. Previous generation of 3D braiding machines: (a) conventional Herzog 3D packing braiding machine; (b) 9-module Herzog 3D rotary braiding machine.

The machine presented here (see Figure 5) illustrates ITA's further development of the rotary 3D braiding concept. It combines high process stability with the flexibility of $3 \mathrm{D}$ braiding technology as a result of the newly developed simulation for 3D braids and matching software for the control of the machine.

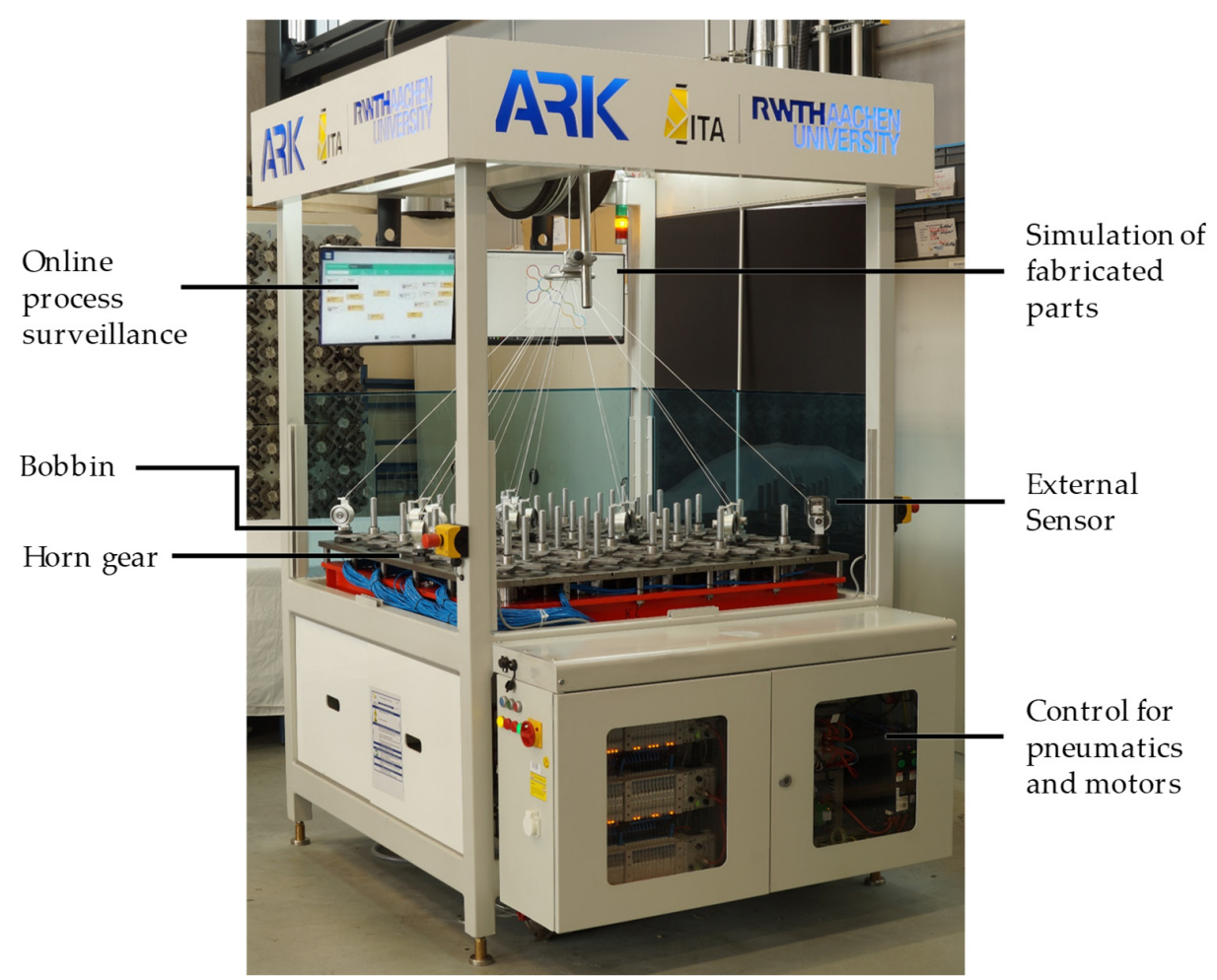

Figure 5. Illustration of the rotary 3D braiding machine at Institut für Textiltechnik (ITA) of RWTH Aachen University, Germany. Adapted from [18]. 
Figure 5 illustrates the newest generation of the 3D rotary braiding machine at ITA, which consists of a machine bed with $5 \times 5$ horn gears, a track as a guide for the bobbins on the machine bed, and pneumatically actuated track-switches. Each horn gear is equipped with a clutch-brake mechanism, which ensures that the rotating horn gears can be stopped in the braiding process. The track-switches are located between adjacent horn gears and are used for the transfer of the bobbins to the next horn gear. To ensure no collision takes place during the $3 \mathrm{D}$ braiding process, the movement of the bobbins needs to be coordinated by simulation prior to the process. With the aid of the online process monitoring system, machine and process parameters are continuously monitored during the process. In addition, further data can be recorded during the process via external sensors which then can be used for process control and quality monitoring. Thus, in combination with the built-in programmable logic controller (PLC) control and the process simulation, an Industry 4.0 standard is achieved with this rotary 3D braiding machine. Simulation in particular plays an important role, as the complexity of the $3 \mathrm{D}$ braiding process requires prior calculation of the individual bobbin paths, the yarns to be processed, and the resulting control parameters in order to achieve high process speed and stability. The machine control software is coupled with the simulation software so that bobbin tracks and the corresponding control of the horn gears and track-switches can be simulated and digitally mapped during the planning and design of the 3D braids to be produced.

The programming of the $3 \mathrm{D}$ rotary braiding machine is based on a MATLAB controller. The internal libraries of MATLAB make it possible to control the machine components via $\mathrm{TCP} / \mathrm{IP}$ or a MODBUS connection [19]. MATLAB is a particularly flexible and powerful software package for solving mathematical problems and, at the same time, provides a suitable solution for graphical representation of results, which is a necessary criterion for the simulation of the 3D braids. The interface between MATLAB and the PLC, i.e., the connected elements, such as frequency converters and FESTO pneumatic air valves, forms the centerpiece of the machine control system. The 3D braiding machine is equipped with a total of two frequency converters from Schneider Electronics. These are each connected to a three-phase motor for the horn gears and for the take-up of the machine. The frequency converters are coupled to the PLC via two digital connections so that independent speeds can be set for the two motors. In addition, three FESTO compressed air valve terminals for controlling the clutch brakes and the track switches are digitally linked to the programmable logic controller. The MODBUS server runs in the background in the operating system of the PLC, which makes it possible to control the 3D braiding machine using about one hundred register values. Thus, the connection of the machine control in MATLAB is done via the internal access to this communication interface. Schematically, this composition is shown in Figure 6.

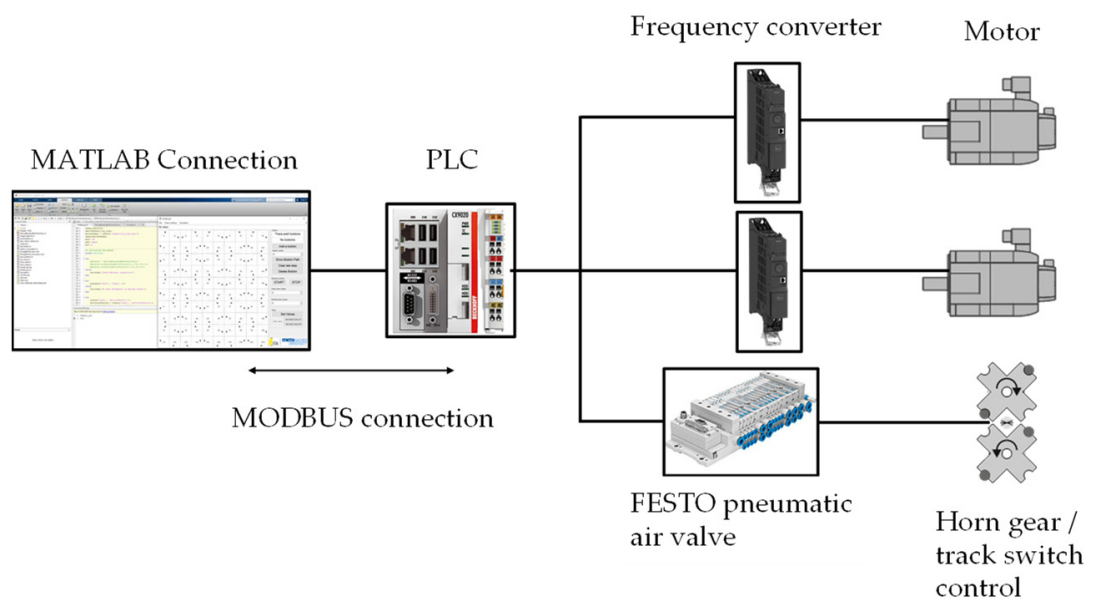

Figure 6. Schematic illustration of the programmable logic controller (PLC) connection. 
For the production of a fiber composite component based on a 3D braided textile semi-finished product, the near-net-shape of the fiber semi-finished product is essential. This ensures that the final component to be manufactured has a constant fiber volume content even after infiltration. To ensure the near-net-shape of the 3D braid with regard to the final composite product, the production of a particularly near-net-shaped 3D braid can thus be calculated and evaluated with the aid of a simulation on the basis of the programmed bobbin tracks and their configuration with the bobbins of the various yarn groups. In addition to the bobbin tracks, the fiber take-off is also included in the simulation. The underlying MATLAB script iterates through all programmed bobbins and simulates the web movement using circular calculations. These are created in sampled distances (Z-axis) and $\mathrm{X}$ and $\mathrm{Y}$ arrays, respectively, as Cartesian coordinates for each bobbin, graphically displayed in an overall plot.

Due to the different lengths of the bobbin tracks of the various yarn groups, a direct 3D plot of all bobbins is not possible. In MATLAB, arrays for graphical 3D plots must always be in the same dimensions. This problem is solved with the help of a replication function for arrays. Thus, all shorter paths (compared to the longest path length) are replicated several times and the 3D plot is created only for the minimum of all array dimensions. This fix corresponds with the practical machine behavior, since the bobbins with shorter track paths move exactly the same distance on the machine bed as the ones with longer track paths (see Figure 3).

The simulation is based on the state-of-the-art technology of the Texmind Braiding Configurator [20], but it is implemented in the software in such a way that the simulation also works for single fibers or double bobbin plaits, detached from all program parameters. Furthermore, the MATLAB script for the simulation can be extended to modified braiding machines with a larger machine bed, modified impellers, etc., so it can also be used for larger braiding machines. In addition, the calculated Cartesian coordinates are available in the standard MATLAB workspace for each individual bobbin and can be used for implementations in, for example, external programs or further MATLAB scripts and graphical representations. Figure 7 shows an example simulation of a double T-profile.

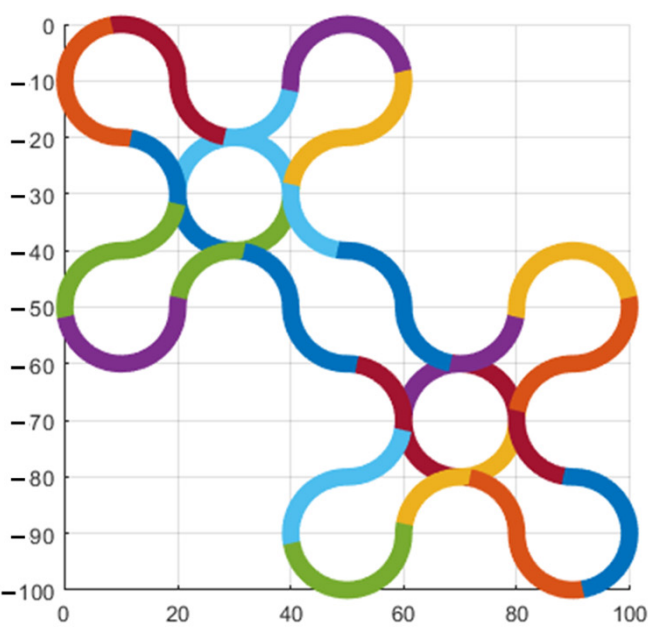

(a)

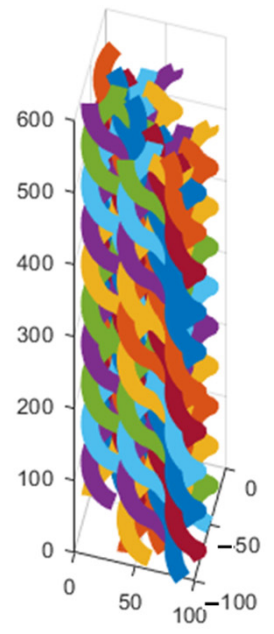

(b)

Figure 7. MATLAB simulation of a 3D braided double T-profile: (a) 2D tracks; (b) 3D simulated image.

The default view shows the 2D tracks of all bobbins. However, using the internal rotation function of three-dimensional MATLAB plots, the simulated image can be rotated like a CAD model. The resulting image corresponds to the $3 \mathrm{D}$ braid with the programmed bobbin positions and bobbin tracks in the real machine setup. 
An example of such a machine setup and its resulting 3D braid is given in Figure 8. It shows the programmed bobbin paths and bobbin configuration for a $3 \mathrm{D}$ braided textile preform, which results in a T-profile-like geometry. For this geometry, there are a total of 32 bobbins required that cross each other on six different bobbin tracks.

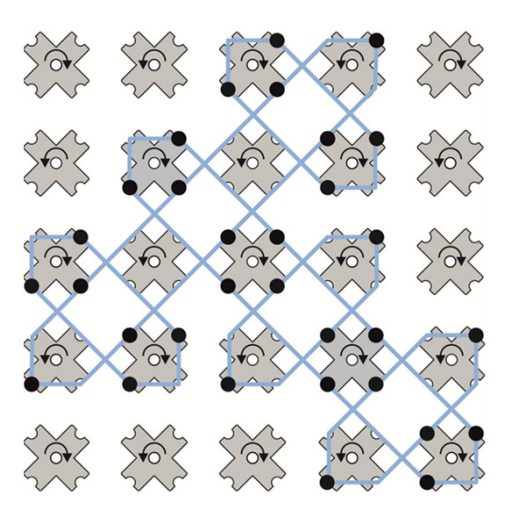

(a)

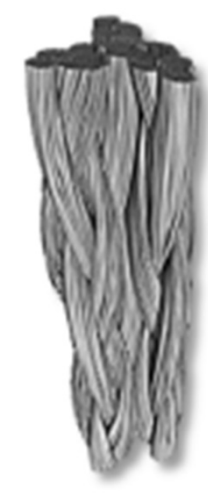

(b)

Figure 8. (a) Programming of bobbin configuration; (b) 3D braided textile preform in a T-profilelike geometry.

Figure 8a shows the bobbin tracks, which are illustrated in blue. The black colored points represent the individual bobbins and their arrangement on the bobbin tracks. Figure $8 \mathrm{~b}$ shows the resulting three-dimensional textile preform in the shape of the Tprofile-like geometry, which was braided with the shown programmed pattern. In this case, $\mathrm{Al}_{2} \mathrm{O}_{3}$ fibers with 10,000 deniers from $3 \mathrm{M}$ Nextel were used [21]. These fibers are relatively brittle compared with carbon fibers or glass fibers. Nevertheless, the fibers could be processed into the complex geometric shape in a process-stable manner on the 3D rotary braiding machine. The process-stable, near-net-shape processing of such oxide ceramic $\mathrm{Al}_{2} \mathrm{O}_{3}$ fibers on a 3D braiding machine provides the basis for the research and development of ceramic matrix composites (CMCs) based on three-dimensional textile reinforcement structures. Current research approaches are related to the mechanical characterization of this material group.

\subsection{Three-Dimensional Hexagonal Braiding Machine}

The hexagonal braider is a 3D braiding machine that can be described as a 3D rotary braiding machine without a track. The transfer of the bobbins takes place by switching mechanisms between the hexagonally arranged horn gears. The kinematics correspond to the sequential movement of a rotary braiding machine. To achieve a high degree of flexibility, the horn gears and switching mechanisms are each equipped with hybrid stepper motors that can be controlled separately. The hybrid stepper motors allow accurate positioning while maintaining high torque due to small step angles.

The unique hexagonal arrangement of the horn gears allows the maximum possible bobbin density. This reduces the distance between the bobbins to the braiding point. This allows a reduction of the yarn length compensation (see Figure 3) in the braiding process and thus a more constant yarn tension. In addition, the friction of the material in the bobbin is minimized. Therefore, the process of 3D hexagonal braiding is particularly suitable for fine materials. Due to its high process flexibility, the method is particularly suitable for the near-net-shape production of tubular structures and ramifications [22]. 
The first generation hexagonal braider was designed and manufactured in cooperation with the Advanced Fibrous Materials Laboratory (AFML) (University of British Columbia, Vancouver, Canada) and ITA (RWTH Aachen University, Aachen, Germany). The machine bed consists of 37 horn gears arranged in three concentric hexagons around a central horn gear (see Figure 9a) The geometry of the horn gears is defined as a regular six-pointed star. Every horn gear can carry a total of six bobbins and can move them in $60^{\circ}$ intervals around the horn gear's center point. Thereby, processing of 132 bobbins and 37 axial yarns is possible. One bobbin occupies the mutual position of two horn gears. Depending on the operating horn gear and the rotational direction, the bobbin may travel in four directions on the braiding loom. The foot of the bobbins is designed as the intersection of the two adjacent circles around the horn gear's center point. The machine speed is $5 \mathrm{~s}$ per step [23].

The second generation hexagonal braiding machine consists of 7 horn gears and 30 switching devices (see Figure $9 \mathrm{~b}$ ). This allows 60 bobbins to be placed on the machine on a machine bed size of $1400 \mathrm{~cm}^{2}$. The main technological development compared to the first generation of the hexagonal braiding machine is the type of bobbin motion. Through the implementation of a switching mechanism, two bobbins can take up the position between two adjacent horn gears. Similar switching devices are used in lace braiding machines $[24,25]$. This doubles the maximum number of bobbins. In contrast to the first generation, as well as to conventional 3D rotary braiding machines, it is possible to use all bobbin positions. Furthermore, machine robustness, speed, flexibility, and control are improved. To ensure the full flexibility of the braiding machine, all horn gears and switching devices are controlled individually by stepper motors. The software is based on LabView and designed to allow and suppress the movement of certain elements in order to avoid collisions. The machine speed is enhanced to below $1 \mathrm{~s}$ per step [26].

In the third generation of the hexagonal braider, the machine mechanics were fundamentally improved. In the second generation, the horn gears and switching mechanisms were made of ultra-high molecular weight polyethylene (PE-UHMW). The horn gears were replaced with metal, and PE-UHMW was retained as the material for the bobbin feet. The changes reduced the coefficient of friction between the components. Furthermore, the wear of the machine bed was minimized [27].

The fourth generation of the hexagonal braiding machine was completed in 2020 (see Figure 9d). The focus of this iteration was the machine software and the renewal of the machine electronics. The stepper motor drive was replaced by new control circuits. The control electronics were previously based on a CAN bus system. The new machine control system consists of two ros2 nodes deployed on individual Raspberry PIs which operate on Ubuntu. The nodes are connected via Ethernet and communicate using the Ros2 framework. Each of the nodes controls half of the stepper motors that are mounted to the machine bed by applying a direction and step signal to the stepper motor drivers. The direction signal is controlled through the i2c bus and the step signals are issued as a hardware clock signal. The use of a hardware clock-controlled signal and an acceleration ramp is decisive for the smooth operation of the stepper motors. One of the nodes acts as the main node which provides a GUI to start, pause, and stop the program, as well as calibration for the motor start positions. The program itself is implemented in Python via a simple interface that allows for definition and reusing of program blocks. The machine development reached a technology readiness level of 7 in this step.

In the future, the braiding process could be monitored, accelerated, and coordinated with further processing through the integration of various sensors. 


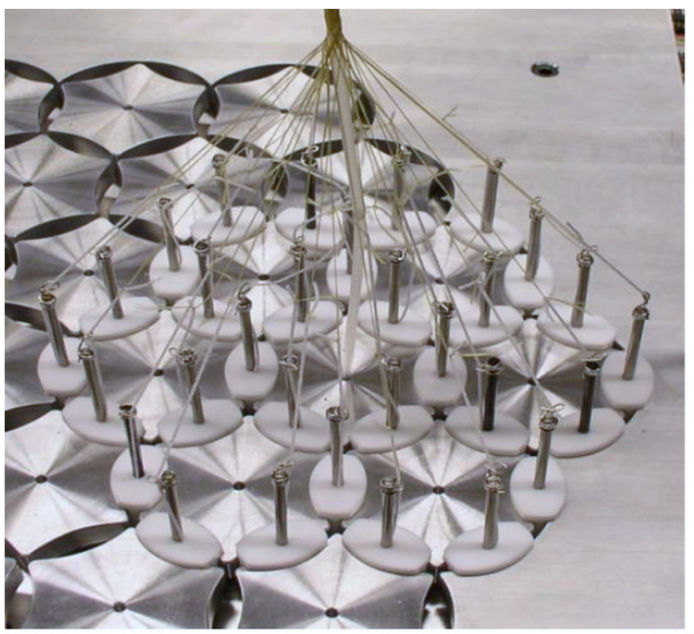

(a)

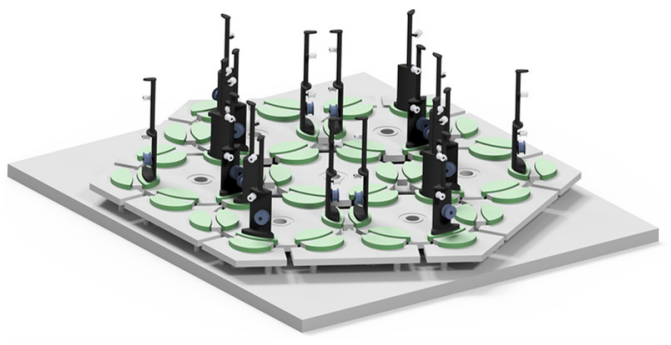

(c)

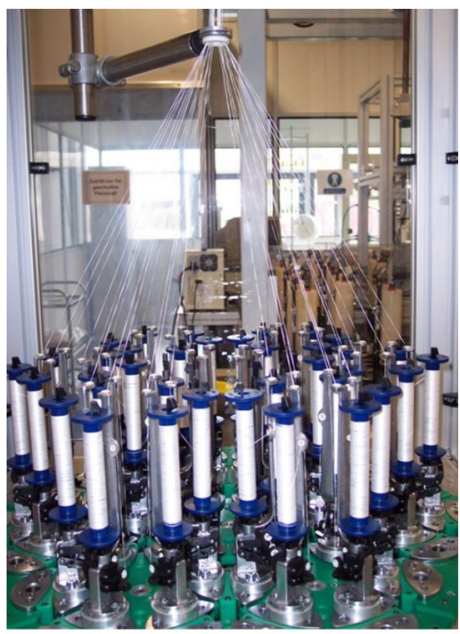

(b)

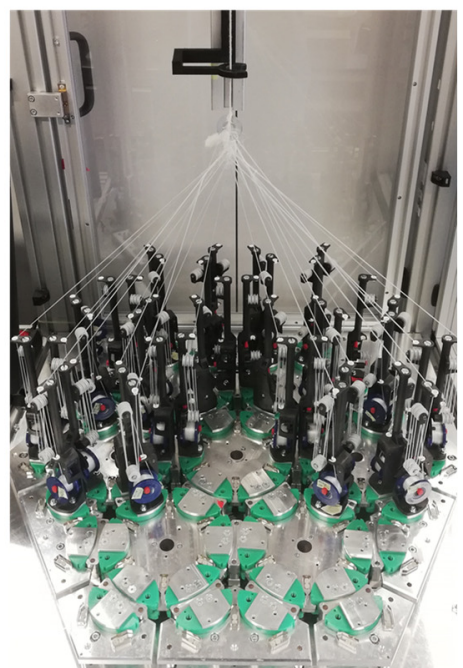

(d)

Figure 9. Illustration of the different generations of the hexagonal 3D braiding machine: (a) Advanced Fibrous Materials Laboratory (University of British Columbia, Vancouver, Canada) (AFML) hexagonal 3D rotary braider (first generation) with 37 horn gears (adapted from ref. [23]); (b) second generation of the 3D hexagonal braider at ITA, with seven horn gears and switching devices (adapted from ref. [27]); (c) CAD scheme of the machine bed from the third generation on; (d) machine bed of the fourth generation of the 3D hexagonal braiding machine.

Table 1 summarizes the described characteristic features of the illustrated rotary and hexagonal 3D braiding machines at ITA. It can be seen from the different sizes of the machines that the fields of application are different. The larger 3D rotary braiding machine $\left(19,600 \mathrm{~cm}^{2}\right.$ machine bed size) is used for technical applications, such as composite lightweight materials, for which glass, carbon, and ceramic fibers are used. The 3D hexagonal braiding machine with the significantly smaller machine bed size of $1400 \mathrm{~cm}^{2}$, on the other hand, is suitable for medical applications, for which nitinol, magnesium, and polymer fibers are used. 
Table 1. Comparison of 3D braiding machines at ITA.

\begin{tabular}{ccc}
\hline Feature & Rotary 3D Braiding Machine & Hexagonal 3D Braiding Machine \\
\hline Size of machine bed & $19,600 \mathrm{~cm}^{2}$ & $1400 \mathrm{~cm}^{2}$ \\
\hline Tracks & Yes & No \\
\hline Process type & Quasi-continuous & 60 \\
\hline Switching device & Pneumatic switch gear & Switching devices inspired by lace braiding \\
\hline Maximum number of bobbins & 48 & 7 \\
\hline Number of horn gears & 25 & Nitinol, magnesium, and polymer fibers \\
(e.g., PCL, PET, PLLA)
\end{tabular}

\section{Applications}

The applications of 3D braided textile semi-finished products differ significantly from conventionally braided textiles. Whereas classic $2 \mathrm{D}$ circular braiding is used for products such as ropes or sheathing for cables, the applications of 3D braiding are adapted to special fields. Due to the complex machine technology and the associated high manufacturing costs of 3D braiding, this process is only suitable for applications that justify the high price, such as lightweight applications or medical textiles.

\subsection{Three-Dimensional Braided Textiles for Lightweight Applications}

Three-dimensional braided semi-finished products as reinforcement preforms for fiber-reinforced composites are of interest where structural elements are subjected to high loads and stresses. Fiber-reinforced plastic composites (FRPCs) are mainly used where the lightweight potential of this material is of great benefit, such as in the mobile and aviation sectors. In addition to the lightweight aspect of 3D-braided FRPCs, the technology of 3D braiding is also of great interest for fiber-reinforced ceramic matrix composites (CMCs). Here, the lightweight aspects of fiber-reinforced composites are combined with the high-temperature properties of ceramics [28,29].

\subsubsection{FRPC}

Three-dimensional composite structures with textile semi-finished products made of 3D braided structures are produced by infiltrating the fiber semi-finished product with a plastic matrix. In the automotive sector, such 3D composite structures are used for loadbearing components, such as the B-pillar (T-like-profile), which must be able to withstand high forces in cases of accidents [5].

In addition to the weight advantage over metallic structures, FRPC structures based on $3 \mathrm{D}$ braided semi-finished products can be used for crash-loaded structures due to their high energy absorption capacity $[5,30]$. With 3D braiding technology, such a near-net-shape T-profile geometry (see Figure 10) can be produced using only one process step. In comparison with a T-shaped geometry formed from an originally flat 2D braid, or alternatively from a flat woven preform, this simplifies the process chain. Furthermore, the intertwining of the layers is responsible for the exhibition of high delamination resistance in cases of high loads and stresses [31]. 


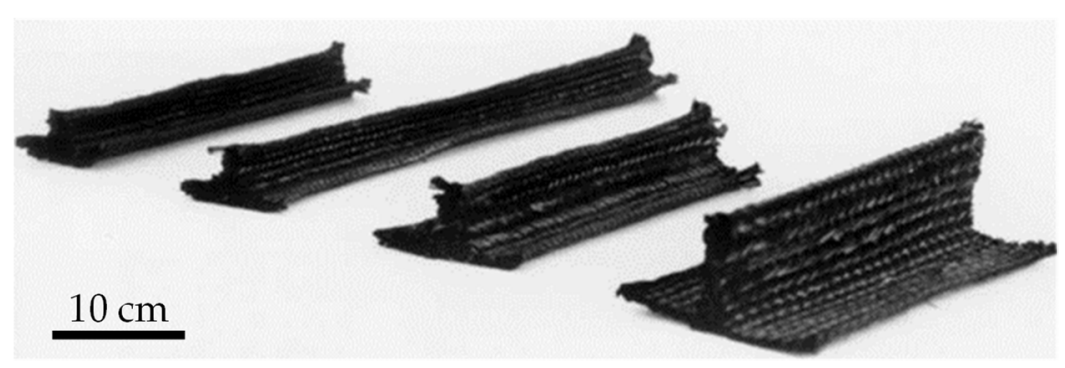

Figure 10. Various 3D braided T-profile-shaped geometries.

With the increasingly advanced 3D braiding technology, the potential application areas in the field of composite structures are simultaneously increasing. The sports industry is an example where conventional materials such as wood have already been replaced with FRPC materials to reduce weight [31]. With increasing shear delamination strength when using 3D braids as the fiber reinforcement, the weight may be further reduced at a constant or increasing quality. Examples that can be mentioned here include tennis rackets and hockey sticks. Furthermore, bicycle frames and bicycle components are an interesting field of application, since safety plays an important role here and improved delamination behavior is of great significance for the safety aspect.

\subsubsection{CMC}

Due to the high brittleness of ceramics, modification is required to increase damage tolerance. With the integration of textile semi-finished products in ceramics, the mechanical properties can be increased compared to monolithic ceramics [32]. However, the use of the 2D fiber-reinforced CMC class of materials remains limited to predominantly thermal applications due to their high shear susceptibility. For example, 2D fiber-reinforced CMCs have a shear strength of $25 \mathrm{MPa}$, which is only $6 \%$ of the flexural strength (400 MPa) [30]. Nevertheless, 2D braided CMCs are already being used in high-temperature applications. For example, the use of a turbine combustor, designed as a fiber composite ceramic, significantly increased the combustion temperature within a PW206 aircraft turbine. This increase resulted in a $20 \%$ reduction in $\mathrm{CO}_{2}$ emissions [33].

3D braiding technology, on the other hand, makes it possible to use CMCs in structural components with higher demands on delamination behavior by connecting the individual layers in all three spatial directions. Of particular interest is the use of such 3D braided components in aircraft turbines, such as in turbine blades. Here, process efficiency can be increased through higher combustion temperatures. Further applications of 3D braided CMCs could include media lines, solar thermal power plants, or solid oxide fuel cells [34].

\subsection{Medical Applications}

Medical textiles are a rapidly growing and versatile area of technical textiles. Braiding is an established production method for manufacturing sutures and stents. Furthermore, the mechanics and morphology of scaffolds can be adapted for tissue engineering applications. Three-dimensional hexagonal braiding offers new possibilities due to the flexibility of the process and the processability of wide-ranging materials $[7,11]$.

\subsubsection{Complex Stent Structures}

While the interventional technique for the treatment of straight vessel or organ sections is already well advanced, the methodology for the treatment of geometrically complex sections is not yet fully developed. In particular, the treatment of vessel or organ branches, so-called bifurcations or trifurcations, is a relevant aspect.

For the treatment of vascular branches, different techniques are used in cardiology, depending on the existing clinical profile. In current procedures, one- or two-stent techniques are mostly used. The one-stent technique is used when the stenosis on the side branch is negligible or the supply area of this vessel is assumed to be negligible. In this 
case, only the main branch is stented and the opening to the side branch is realized by means of balloon dilatation. When using the two-stent technique, different procedures are used depending on the case at hand, e.g., the Coulotte technique, T-stenting, crush stenting, Y-stenting, or the kissing stent technique $[35,36]$.

Interventions using the known techniques take a long time and require a large amount of contrast medium as well as long X-ray fluoroscopy times for precise placement of the stents. In addition, in cases of the "crush", "coulotte", or "kissing stent" techniques, for example, there is an increased mechanical stent load depending on the type of insertion and positioning. This affects the mechanical load-bearing capacity of the stent branches $[37,38]$.

The use of a single bifurcation stent to cover the entire bifurcation simplifies the intervention and thus the extent of the procedure. In addition, the patient and the material are spared, which means that better long-term results can be expected. Current existing models are manufactured manually or by laser cutting. There is also potential for optimization in the area of pulmonary or gastrointestinal organs with regard to the automation of the previously manual production of bifurcation stents. Becker et al. first demonstrated promising possibilities on the development of braided bifurcation stents by variation braiding [39].

The development and manufacture of complex Nitinol stent structures with the 3D hexagonal braiding machine is based, on the one hand, on the development of a suitable braiding core and, on the other hand, on the development of the braiding process.

The modular braiding core (see Figure 11b) was developed based on VDI guideline 2221 ("Systematic approach to the development and design of technical systems and products"). For this purpose, the sub-functions of guiding the braiding core in the hexagonal braiding machine fixing the filaments to the core as well as the hinge area of the braiding core, were considered.

The geometric requirements are decisive for the development of the braided core. Commercially available stents have diameters of 5-24 mm, depending on the area of application, with branch lengths varying strongly. Since the present work focuses on the design and the braiding process, average values are assumed for the geometrical data. Therefore, a core diameter of $15 \mathrm{~mm}$ and branch lengths of the main branch and secondary branches of $60 \mathrm{~mm}$ are defined as representative geometries. Since a modular system with variable branch length is being developed, there is the possibility of extending the secondary branches by $20 \mathrm{~mm}$. The bifurcation angle is the angle between the secondary branches of the branch. The bifurcation angles of vessels can theoretically vary greatly between $1^{\circ}$ and $179^{\circ}$, especially in the vascular area. In order to be able to represent common values, the bifurcation angles to be produced are set to values between $30^{\circ}$ and $180^{\circ}$. In addition to the realization of different bifurcation angles, the stent core should allow the production of different stent shapes. Both bifurcation and J-stents are to be realized. This requires a modular design, which allows the targeted addition and removal of stent branches.

In addition to the geometric requirements, the demoldability in the braided state must be taken into account, in particular when developing the concepts. It must subsequently be possible to remove the branches of the braided core axially from the braid. Furthermore, the technical design should aim for a mechanism that is as simple as possible, which on the one side is insensitive to thermal loads and on the other side can be transferred to braided cores for stents with smaller diameters in the context of modular product design.

A fixation ring is used to fix the filaments to the main branch of the braiding core at the start of the braiding process. The fixation ring can be moved axially on the main branch so that the length of the braid can be adjusted as required on the main branch. In the hinge area of the braiding core, the node cover realizes a continuous outer geometry. In addition, together with the fixing screw, it serves to lock the angle after setting the desired braiding angle. The secondary branches of the braiding core have narrowed surfaces in the upper area in order to be able to realize small bifurcation angles. The branches can be modularly extended by means of a screw connection. 
The approach to developing the braiding processes for complex stent structures is to abstract them into several basic structures that are easy to realize and for which braiding strategies are known. The basic structures include round and flat braids, as well as triangular or square profiles. Based on the determined product requirements, a transformation is developed which realizes a reasonable transport of the filaments during the transition between the basic braids. It is necessary to match the desired parameters of the basic structures to be realized with the possible parameters of the braiding machine. The boundary conditions include, for example, the required number of yarns, the desired bobbin density, the desired braiding angle, and the braiding pattern. When developing the strategy, the structural interdependence of the basic braids must be taken into account. Since this is a stationary process with a constant number of yarns at the product level, the sum of all the filaments involved in the process must always remain constant.

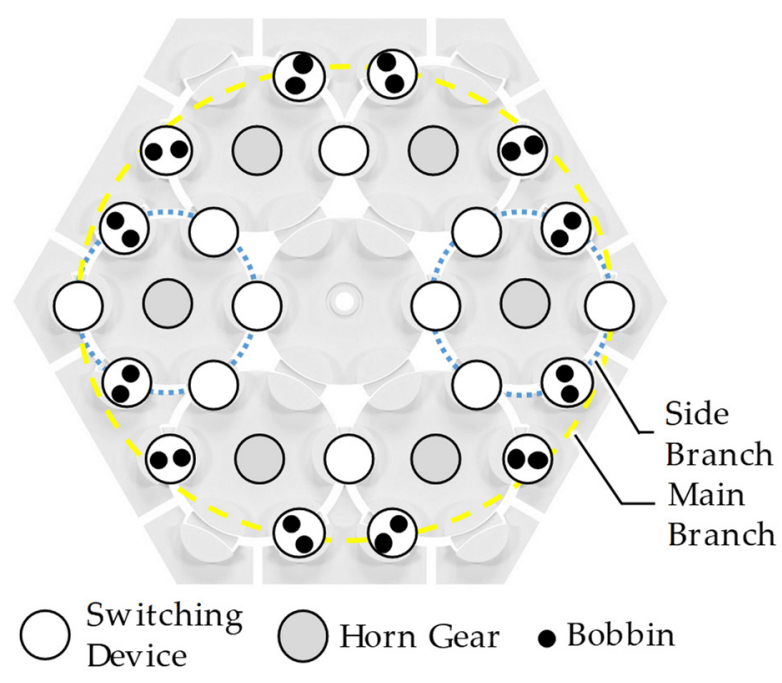

(a)

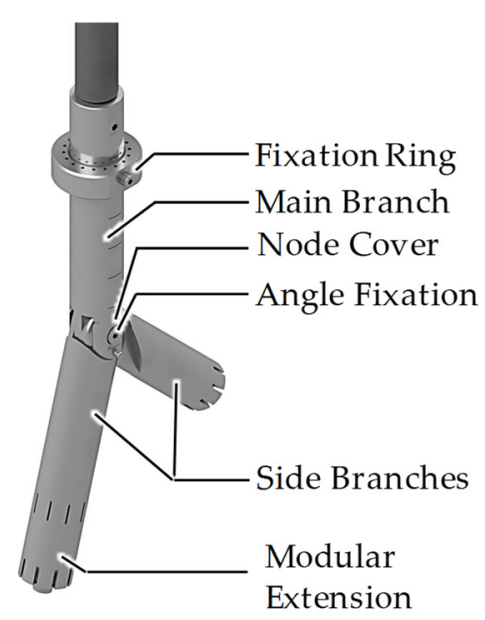

(b)

Figure 11. (a) Scheme of the machine bed of the 3D hexagonal braiding machine with the braiding track shown for a bifurcation stent (main branch (yellow track) and side branches (blue track)); (b) CAD drawing of the modular braiding core for complex stent structures.

A bifurcation stent is a branched circular braid, which can be abstracted into three circular braids and a nodal region. Since the two round braids of the secondary branches are identical braids, the development of a corresponding braiding strategy involves the realization of two different round braiding processes and a corresponding transformation. In the abstraction, it must be taken into account that the filaments run continuously through the stent and that the sum of all filaments is constant. The filament count is 24 filaments for the main branch and 12 filaments each for both secondary branches. The braiding structure is set to a 1:1-1 braiding pattern, because this braiding pattern provides the best matching of material density and high radial force. The radial force is an essential property for anchoring the stent to prevent migration after implantation and to ensure the hollow organ is kept open.

The braiding process of the round braids is based on the braiding process of conventional round braiding machines. This process is imitated on the 3D hexagonal braiding machine by the sequential movement of the bobbins. For a homogeneous braiding pattern, it is essential to have a braiding track that is symmetrical around the braiding axis. The bobbins are located on two concentric circles. While the outer circle defines a rest position, the bobbins are rotated around the braiding axis on the inner circle. The basic principle of the sequential movement can be described in four repeating basic steps: clockwise rotation of the right-turning bobbins (1), crossing of the left-turning bobbins by leading them under 
the right-turning bobbins (2), counterclockwise rotation of the left-turning bobbins (3), crossing the right-turning bobbins by passing them under the left-turning bobbins (4).

For the main branch, the outermost track of the machine bed is used. Twenty-four bobbins are symmetrically distributed on the outer six horn gears. For the side branches, the round braid is produced by twelve bobbins arranged around one horn gear, respectively. The starting position of the bobbins as along with the braiding track for the main and side branches are shown in Figure 11a.

The node describes the point of contact of the two round braids in the intersection of the side branches. The node point is closed by crossing the last filament in the node point. From a technical point of view, the filaments change their direction of rotation at the node point and thus switch to the other branch in the opposite direction. With one filament per direction of rotation and stent branch, this results in four filaments closing the node. This method is characterized by good support and direct force transmission of the filaments involved. This ensures high stability of the node under both tensile and compressive forces.

The J-stents (see Figure 12) are manufactured analogously to the main branch of the Y-stents. The stents are braided on the developed braiding core, bent by a defined angle following the braiding process, and then thermally fixed. Based on the core design, a kink angle between $0-90^{\circ}$ can be achieved.

By adapting the braiding process, it is possible to produce patient-specific stent geometries. In addition to individual bifurcation angles and diameter changes, this also includes the insertion of cutouts in the stent structure (see Figure 12). Furthermore, the cutouts offer the possibility of anchoring a second stent in the structure without damaging the primary stent structure. The structure can also be dissected into different basic braids, in this case into a round and a flat braid. By changing to the flat braid, the cutout is created and the edge is mechanically reinforced by the targeted filament deposition (see Figure 12b). The combination of J-stents with patient-specific cutouts in the stent is possible due to the modular core design.

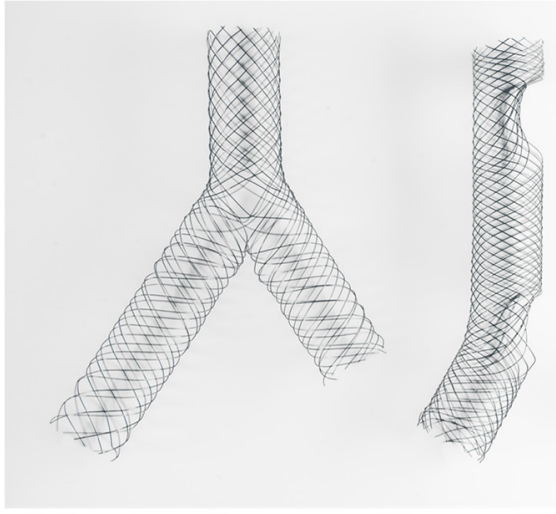

(a)

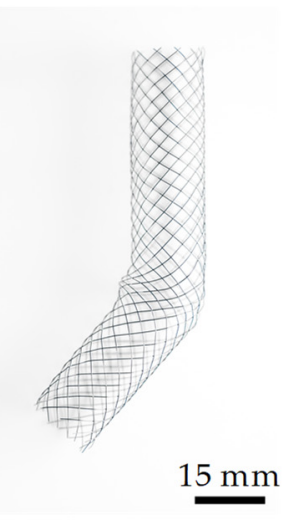

$5 \mathrm{~mm}$

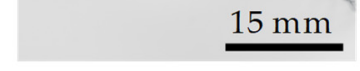

(b)

Figure 12. Complex nitinol stent structures manufactured by 3D hexagonal braiding: (a) bifurcation stent, stent with patient individualized cutouts, and J-stent with a diameter of $15 \mathrm{~mm}$; (b) close-up of the cutouts created by changing the braiding pattern from a round to a flat braid.

\subsubsection{Artificial Ligaments}

The anterior cruciate ligament (ACL) is one of the most important stabilizing structures in the knee. It is a bundle of fibers about $30 \mathrm{~mm}$ long and about the thickness of a small finger that extends from the head of the tibia to the femur in the knee joint $[40,41]$. 
During strong bending or twisting movements, such as in soccer or skiing accidents, an unfavorable lever movement occurs that can no longer be held by the muscles, causing the anterior cruciate ligament to tear. When the cruciate ligament tears, chronic instability of the knee joint develops. The joint kinematics change and the additional stress is placed on the remaining structures, such as the ligaments, menisci, and cartilage of the joint. To prevent secondary damage, the ligament should be reconstructed. Due to the avascular structure of the ligament, spontaneous healing is not possible in the event of a tear [41].

Currently, autologous grafts represent the gold standard for cruciate ligament replacement. Mostly the patellar tendon or the semitendinosus tendon is used. The disadvantages of all autologous grafts are the quality of the autograft, the weakening of the tissue at the donor site, and the limited availability. The autologous replacement tissues do not have the same microanatomical structure or mechanical properties, i.e., stiffness and maximum tensile strength, as the ACL [42,43].

In the 1980s, synthetic materials were increasingly used as cruciate ligament implants. In retrospect, it must be noted that the materials used to replace the anterior cruciate ligament were not adequate to the requirements. Although the replacement materials were able to achieve good results for a short period after reconstruction, they failed with regard to long-term use. The causes were insufficient mechanical properties, such as abrasion, frequent material fatigue, or even poor integration into the bone tissue. Most of the non-degradable, synthetic ligaments are no longer in clinical use [44].

In recent years, interest has grown in tissue-engineered solutions for ligament replacement. An ideal scaffold for cruciate ligament replacement must be able to withstand the mechanical loads for the regeneration period on the one hand and, on the other hand, allow the regeneration of the ligament on a biological level through biocompatibility, biodegradability, and porosity. Several groups have shown results based on braided degradable scaffolds [45-50].

In the following, the approach involving degradable ACL scaffolds based on a 3D hexagonal braiding technique is described. The design of the scaffold as a 3D braid offers several advantages. For the in situ tissue engineering approach, a cell guidance structure is required. Due to the individual filament deposition in all spatial directions, this guiding structure can be designed for uniform three-dimensional ingrowth. Furthermore, the load distribution under tensile load as well as the friction are optimized, in contrast to a multilayer round braid.

The design of the scaffold can have different priorities; for example, the shape can be inspired by the anatomical structure of the native cruciate ligament or the friction of the structure can be optimized.

In Figure 13, different scaffold designs are shown. The scaffolds have a constant filament count of 252 filaments distributed over 36 bobbins and are made of poly- $\varepsilon$ caprolactone.

The "three-tube braid" is a braid that consists of three interconnected round braids. The design is based on the structure of the native cruciate ligament with its three bundles (the anterior-medial, posterior-lateral, and intermediate bundles). The "six-tube braid" is a scaling of the "three-tube braid". The six individual round braids are connected analogously in the middle. The "multilayer braid" consists of two intertwined layers. Due to the interconnected core-sheath structure, the braid is optimized for three-dimensional cell ingrowth and provides a continuous connection between the two layers. 


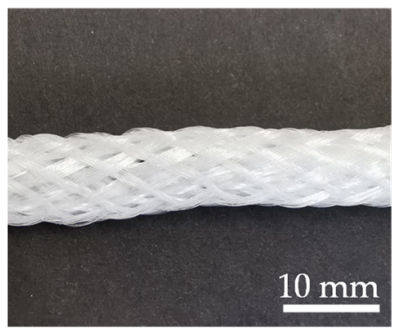

(a)

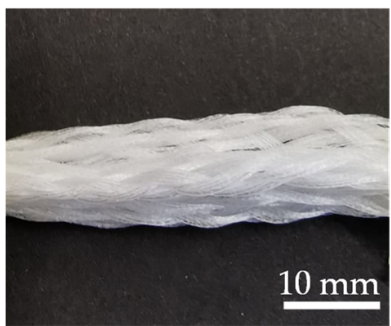

(d)

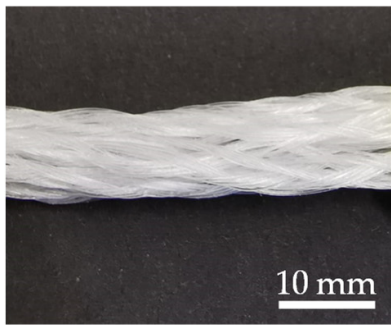

(g)

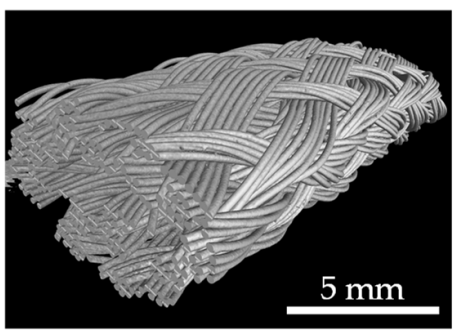

(b)

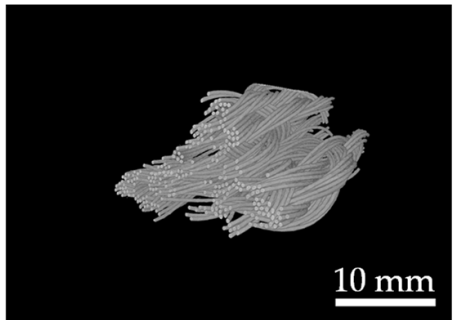

(e)

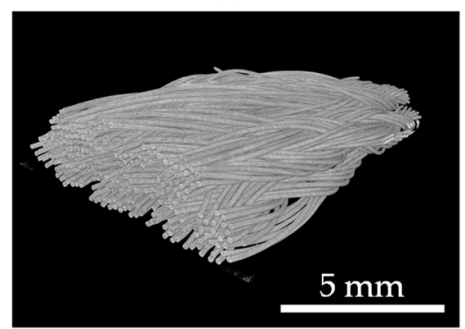

(h)

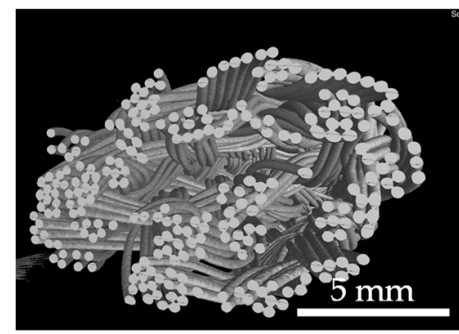

(c)

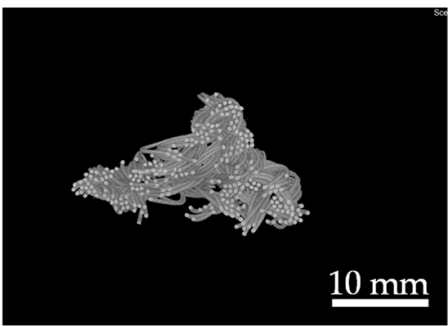

(f)

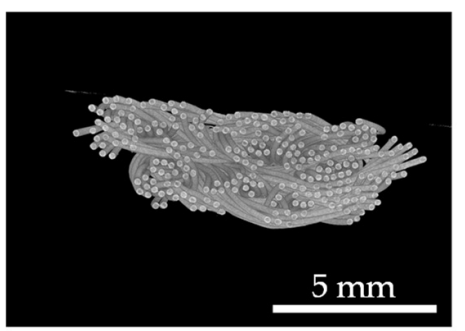

(i)

Figure 13. Different 3D braided scaffold designs manufactured on the 3D hexagonal braiding machine: (a-c) "multilayer braid", (d-f) "three-tube braid", (g-i) "six-tube braid"; (a,d,g) photographs, $(\mathbf{b}, \mathbf{c}, \mathbf{e}, \mathbf{f}, \mathbf{h}, \mathbf{i})$ micro-computed tomography $(\mu-\mathrm{CT})$ scans.

Due to the complex braid structures and the versatile development possibilities of new braid geometries, simulation provides a good basis for the pre-selection and suitability of new braid geometries for ACL replacement. The simulation is based on a MATLAB model and is comparable to the simulation of Zhengning et al. [51]. The MATLAB model at ITA corresponds to the machine bed of the hexagonal braider in generations two to four. The course of the individual filaments is implemented in a CAD model based on the coordinates. Finally, the CAD model is meshed in Abaquus and an FEM simulation of the tensile test is performed.

In the further course of our work, the braids will be characterized mechanically, morphologically, and biologically to determine their suitability as scaffolds for in-situ tissue engineering for ligament replacement.

\section{Conclusions and Future Innovations}

Despite the presented innovations in the field of digitalization of the latest generation of 3D braiding machines at ITA, the topic still offers further development opportunities in the future.

In both the 3D rotary braiding machine and the 3D hexagonal braider, the integration of further sensor technology for monitoring the braiding process could offer an expansion of the process stability, speed, and quality control. This could include, for instance, sensors for monitoring the position of the bobbins and monitoring of the braiding point with integrated control of the take-off speed. Based on this further development, the monitoring of the entire process chain could be addressed and extended.

The development of complex braiding patterns is still a challenge in terms of avoiding bobbin collisions and errors in the braiding pattern. In this area, the development of an algorithm to create braiding patterns based on the data from previous 3D braids could be 
facilitating. Such an algorithm would be of particular interest for the production of 3D braids with more complex geometry and greater dimensions.

In order to expand the fields of application of the 3D braiding machines, the extension of the hexagonal braider to a larger machine bed should be addressed. In this way, the high packing density of the switching devices could also be used in the field of braided reinforcement preforms for lightweight composite materials. Thereby, larger and more complex cross-sections could be implemented. For the processing of glass and carbon fibers, the adaptation of the bobbins to the switching devices would be necessary.

In future generations of $3 \mathrm{D}$ braiding machines, electromagnetic control of the machines is a possibility to simplify the $3 \mathrm{D}$ braiding process, as it would no more be limited to the mechanics of the horn gears and bobbin tracks. Hence, this would shorten the setup time of the process but also, more importantly, increase the flexibility of the 3D braiding machine technology and therefore increase the accuracy and precision of the near-net-shape 3D braid geometry.

Author Contributions: Conceptualization, C.E., N.G., B.V., F.M., A.I., J.S.; methodology, C.E., N.G., B.V., F.M.; software, B.V.; investigation, C.E., N.G., B.V., F.M.; writing-original draft preparation, C.E., N.G.; writing—review and editing, C.E., N.G., B.V., F.M., A.I., J.S., T.G.; supervision, A.I., J.S., T.G. All authors have read and agreed to the published version of the manuscript.

Funding: ITA Technologietransfer GmbH, Aachen, supported the development of the 3D hexagonal braider. The parts of the project for the newest development of the rotary $3 \mathrm{D}$ braiding machine were funded by the Deutsche Forschungsgemeinschaft (GR 1311/73-1).

Institutional Review Board Statement: Not applicable.

Informed Consent Statement: Not applicable.

Data Availability Statement: No new data were created or analyzed in this study. Data sharing is not applicable to this article.

Acknowledgments: We want to thank Gier Automation, Inhaber Max Gier, and ark Industrie AG for the successful cooperation in the process of the software development.

Conflicts of Interest: The authors declare no conflict of interest.

\section{References}

1. Gries, T.; Veit, D.; Wulfhorst, B. Geflechtherstellung. In Textile Fertigungsverfahren: Eine Einführung; Hanser: München, Germany, 2019; pp. 235-240, ISBN 978-3-446-45684-6.

2. Bilisik, K. Three-dimensional braiding for composites: A review. Text. Res. J. 2012, 83, 1414-1436. [CrossRef]

3. Bilisik, K. Cartesian 3D braiding. In Advances in Braiding Technology; Elsevier BV: Amsterdam, The Netherlands, 2016; pp. 107-145.

4. Kostar, T.D.; Chou, T.-W. A methodology for Cartesian braiding of three-dimensional shapes and special structures. J. Mater. Sci. 2002, 37, 2811-2824. [CrossRef]

5. Yamamoto, T.; Hirokawa, T. Advanced Joint of 3D Composite Materials for Space Structure. In Proceedings of the 35th International SAMPE Symposium, Anaheim, CA, USA, 2-5 April 1990; pp. 1069-1077.

6. D'Amora, U.; Gloria, A.; Ambrosio, L. Composite materials for ligaments and tendons replacement. In Biomedical Composites; Elsevier BV: Amsterdam, The Netherlands, 2017; pp. 215-235.

7. Aibibu, D.; Hild, M.; Cherif, C. An overview of braiding structure in medical textile. In Advances in Braiding Technology; Elsevier BV: Amsterdam, The Netherlands, 2016; pp. 171-190.

8. Bogdanovich, A. An overview of three-dimensional braiding technologies. In Advances in Braiding Technology; Elsevier BV: Amsterdam, The Netherlands, 2016; pp. 3-78.

9. Potluri, P.; Nicolais, L. Braiding. In Wiley Encyclopedia of Composites; Wiley: Hoboken, NJ, USA, $2012 ;$ p. 020.

10. Guyader, G.; Gabor, A.; Hamelin, P. Analysis of 2D and 3D circular braiding processes: Modeling the interaction between the process parameters and the pre-form architecture. Mech. Mach. Theory 2013, 69, 90-104. [CrossRef]

11. Chellamani, K.; Sudharsan, J.; Sathish, J. Medical Textiles Using Braiding Technology. In Journal of Academia and Industrial Research (JAIR); JAIR: Chennai, India, 2015.

12. Ko, F.K. Handbook of Industrial Braiding; Atkins and Pearce: Covington, KY, USA, 1989.

13. Kyosev, Y. (Ed.) Advances in Braiding Technology: Specialized Techniques and Applications; Woodhead Publishing Series in Textiles; Woodhead Publishing: Oxford, UK, 2016; ISBN 978-0-08-100926-0.

14. Kyosev, Y. Braiding Technology for Textiles; Woodhead Publishing Series in Textiles; Woodhead Publishing: Waltham, MA, USA, 2014; ISBN 978-0-85709-135-2. 
15. Tsuzuki, M. Threedimensional Fabric Woven by Interlacing Threads with Rotor Driven Carriers. U.S. Patent 5067525a, 26 November 1991.

16. Kostar, T.D.; Chou, T.-W. Process simulation and fabrication of advanced multi-step three-dimensional braided preforms. J. Mater. Sci. 1994, 29, 2159-2167. [CrossRef]

17. Herzog GmbH. Flecht- Und Spulmaschinen Vom Marktführer. Oldenburg, Germany. Available online: www.herzog-online.com (accessed on 1 May 2021).

18. Grigat, N.; Kolloch, M.; Sackmann, J.; Praß, N. Retrofitting of Textile Machines for an Efficient Digital Production. Text.4U Texdata Int. Mag. 2020, 1/2, 62-63.

19. MODBUS Communication -MATLAB \& Simulink-MathWorks Deutschland. Available online: www.mathworks.com (accessed on 23 April 2021).

20. TexMind-Software and Consulting for Textiles. Available online: www.texmind.com (accessed on 5 May 2021).

21. 3MTM NextelTM Roving 610. Available online: https://www.3mdeutschland.de/3M/de_DE/p/d/b40066332/ (accessed on 17 September 2020).

22. Schreiber, F. Three-dimensional hexagonal braiding. In Advances in Braiding Technology; Elsevier BV: Amsterdam, The Netherlands, 2016; pp. 79-88.

23. Schreiber, F.; Ko, F.K.; Yang, H.-J.; Amalric, E.; Gries, T. Novel Three-Dimensional Braiding Approach and Its Products. In Proceedings of the ICCM-17: 17th International Conference on Composite Materials, IOM Communications: Edinburgh International Convention Centre (EICC), Edinburgh, UK, 27-31 July 2009.

24. Mungalov, D.; Bodanovich, A. Automated 3D Braiding Machine and Method. U.S. Patent 6,439,096, 27 August 2002.

25. Bogdanovich, A.; Mungalov, D. Recent Advancements in Manufacturing 3D Braided Preforms and Composites. In Proc ACUN-4 Composite Systems-Macro Composites, Micro Composites, Nanocomposites; University of New South Wales: Sydney, Australia, 2002.

26. Schreiber, F.; Theelen, K.; Schulte Südhoff, E.; Lee, H.; Ko, F.; Gries, T. 3D-Hexagonal Braiding: Possibilities in near-Net Shape Preform Production for Lightweight and Medical Applications. In Proceedings of the 18th International Conference on Composite Materials, Jeju Island, Korea, 21-26 August 2011.

27. Bach, C.; Schreiber, F.; Theelen, K.; Schulte Südhoff, E.; Lee, H.-Y.; Ko, F.K.; Gries, T. 3D Hexagonal Braiding: Opportunities for Manufacturing Complex Braided Structures. Inst. Text. RWTH Aachen Univ. 2012, 59, 99.

28. Krenkel, W. (Ed.) Deutsche Gesellschaft für Materialkunde. In Keramische Verbundwerkstoffe: DGM-Seminar "Keramische Verbundwerkstoffe", Veranstaltet am 19. und 20.11.2002 in Stuttgart; Wiley-VCH [u.a.]: Weinheim, Germany, 2003; ISBN 978-3-527-30529-2.

29. Bansal, N.P.; Lamon, J.; American Ceramic Society (Eds.) Ceramic Matrix Composites: Materials, Modeling and Technology; Wiley: Hoboken, NJ, USA, 2015; ISBN 978-1-118-23116-6.

30. Textile Werkstoffe für den Leichtbau; Cherif, C. (Ed.) Springer: Berlin/Heidelberg, Germany, 2011; ISBN 978-3-642-17991-4.

31. Bulat, M.; Ahlborn, H.; Gnädinger, F.; Michaelis, D. Braided carbon fiber composites. In Advances in Braiding Technology; Elsevier BV: Amsterdam, The Netherlands, 2016; pp. 383-394.

32. American Ceramic Society. Ceramic engineering and science proceedings. In Mechanical Properties and Performance of Engineering Ceramics and Composites IX: A Collection of Papers Presented at the 38th International Conference on Advanced Ceramics and Composites, 26-31 January 2014, Daytona Beach, Florida; [Papers Presented in the Mechanical Behavior and Performance of Ceramics E Composites Symposium during the 38th International Conference $\mathcal{E}$ Exposition on Advanced Ceramics and Composites (ICACC)]; Singh, D., Ed.; Wiley: Hoboken, NJ, USA, 2015; ISBN 978-1-119-03118-5.

33. Bhatia, T.; Jarmon, D.; Shi, J.; Kearney, S.; Kojovic, A.; Hu, J.; Prociw, A. CMC Combustor Liner Demonstration in a Small Helicopter Engine. In Proceedings of the Volume 1: Aircraft Engine; Ceramics; Coal, Biomass and Alternative Fuels; Education; Electric Power; Manufacturing Materials and Metallurgy; ASMEDC: Glasgow, UK, 2010; pp. 509-513.

34. Krenkel, W. (Ed.) Ceramic Matrix Composites: Fiber Reinforced Ceramics and Their Applications; Wiley-VCH: Weinheim, Germany, 2008; ISBN 978-3-527-31361-7.

35. Lee, J.M.; Park, K.W.; Koo, B.-K.; Kim, H.-S. Stenting of Coronary Bifurcation Lesions: A Literature and Technical Review. Curr. Cardiol. Rep. 2015, 17, 45. [CrossRef] [PubMed]

36. Latib, A.; Colombo, A.; Sangiorgi, G.M. Bifurcation stenting: Current strategies and new devices. Heart 2008, 95, 495-504. [CrossRef]

37. Melikian, N.; Di Mario, C. Treatment of bifurcation coronary lesions: A review of current techniques and outcome. J. Interv. Cardiol. 2003, 16, 507-513. [CrossRef] [PubMed]

38. Waksman, R.; Bonello, L. The 5 Ts of Bifurcation Intervention: Type, Technique, Two Stents, T-Stenting, Trials. JACC Cardiovasc. Interv. 2008, 1, 366-368. [CrossRef]

39. Becker, M.; Ficker, F.; Miksch, R. Variation Braiding Technology by the Example of Novel Stent Structures. In Proceedings of the STRUTEX 2018, Liberec, Czech Republic, 4 December 2018; Volume 1, pp. 11-13.

40. Putz, R.; Mühlhofer, H.; Ercan, Y. Bänder des Kniegelenks. Der Orthopäde 2007, 36, 612-619. [CrossRef] [PubMed]

41. Girgis, F.G.; Marshall, J.L.; Jem, A.R.S.A.M. The Cruciate Ligaments of the Knee Joint. Clin. Orthop. Relat. Res. 1975, 106, $216-231$. [CrossRef] [PubMed]

42. Wilcke, A. Vordere Kreuzbandläsion Anatomie Pathophysiologie Diagnose Therapie Trainingslehre Rehabilitation; Springer: Berlin/Heidelberg, Germany, 2004; ISBN 978-3-7985-1958-9. 
43. Fu, F.H.; Schulte, K.R. Anterior Cruciate Ligament Surgery 1996: State of the Art? Clin. Orthop. Relat. Res. 1996, 325, 19-24. [CrossRef]

44. Batty, L.M.; Norsworthy, C.J.; Lash, N.J.; Wasiak, J.; Richmond, A.K.; Feller, J.A. Synthetic Devices for Reconstructive Surgery of the Cruciate Ligaments: A Systematic Review. Arthrosc. J. Arthrosc. Relat. Surg. 2015, 31, 957-968. [CrossRef]

45. Cooper, J.A.; Lu, H.H.; Ko, F.K.; Freeman, J.W.; Laurencin, C.T. Fiber-based tissue-engineered scaffold for ligament replacement: Design considerations and in vitro evaluation. Biomaterials 2005, 26, 1523-1532. [CrossRef] [PubMed]

46. Silva, M.; Ferreira, F.N.; Alves, N.M.; Paiva, M.C. Biodegradable polymer nanocomposites for ligament/tendon tissue engineering. J. Nanobiotechnol. 2020, 18, 1-33. [CrossRef]

47. Costa-Almeida, R.; Domingues, R.M.; Fallahi, A.; Avci, H.; Yazdi, I.K.; Akbari, M.; Reis, R.L.; Tamayol, A.; Gomes, M.E.; Khademhosseini, A. Cell-laden composite suture threads for repairing damaged tendons. J. Tissue Eng. Regen. Med. 2017, 12, 1039-1048. [CrossRef]

48. Barber, J.G.; Handorf, A.M.; Allee, T.J.; Li, W.-J. Braided Nanofibrous Scaffold for Tendon and Ligament Tissue Engineering. Tissue Eng. Part A 2013, 19, 1265-1274. [CrossRef]

49. Ramakrishna, H.; Li, T.; He, T.; Temple, J.; King, M.W.; Spagnoli, A. Tissue engineering a tendon-bone junction with biodegradable braided scaffolds. Biomater. Res. 2019, 23, 11. [CrossRef]

50. Mengsteab, P.Y.; Freeman, J.; Barajaa, M.A.; Nair, L.S.; Laurencin, C.T. Ligament Regenerative Engineering: Braiding Scalable and Tunable Bioengineered Ligaments Using a Bench-Top Braiding Machine. Regen. Eng. Transl. Med. 2020, 1-9. [CrossRef]

51. Zhengning, L.; Haichen, L.; Ge, C.; Frank, K. Simulation and characterization of circular hexagonal braiding fabricstructure. Ind. Text. 2020, 71, 23-27. [CrossRef] 